\title{
DENTAL PULP INFLAMMATORY/IMMUNE RESPONSE TO A CHITOSAN-ENRICHED FIBRIN HYDROGEL IN THE PULPOTOMISED RAT INCISOR
}

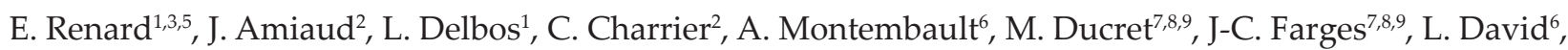 \\ B. Alliot-Licht ${ }^{1,3,4}$ and A. Gaudin ${ }^{3,4,10, *}$
}

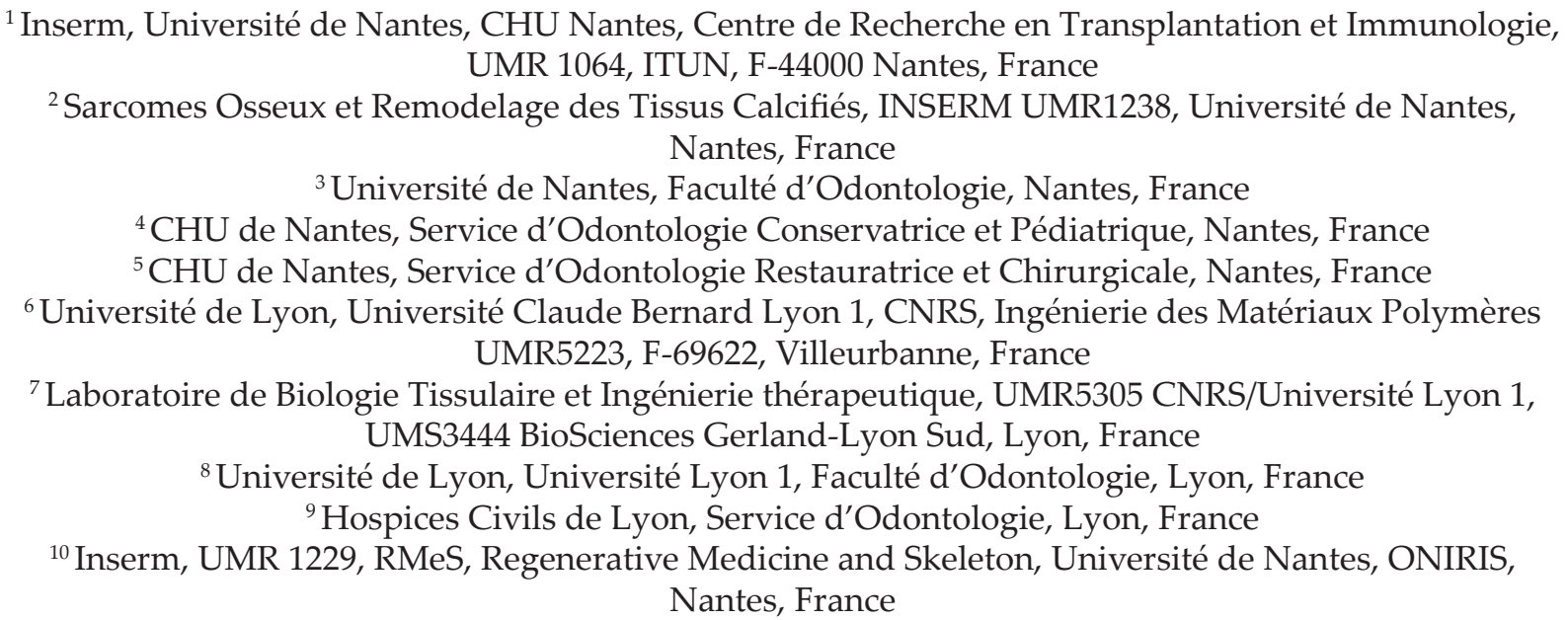

\begin{abstract}
Current pulpotomy is limited in its ability to induce regeneration of the dental-pulp (DP) complex. Hydrogels are reported to be well-suited for tissue engineering and are unlikely to induce an inflammatory response that might damage the remaining tissue. The present study investigated the molecular and cellular actors in the early inflammatory/immune response and deciphered M1/M2 macrophage polarisation to a chitosanenriched fibrin hydrogel in pulpotomised rat incisors. Both fibrin and fibrin-chitosan hydrogels induced a strong increase in interleukin-6 (IL-6) transcript in the DP when compared to the DP of untreated teeth. Gene expression of other inflammatory mediators was not significantly modified after $3 \mathrm{~h}$. In the viable DP cell population, the percentage of leukocytes assessed by flow cytometry was similar to fibrin and fibrinchitosan hydrogels after $1 \mathrm{~d}$. In this leukocyte population, the proportion of granulocytes increased beneath both hydrogels whereas the antigen-presenting cell, myeloid dendritic cells, $\mathrm{T}$ cells and B cells decreased. The natural killer (NK) cell population was significantly decreased only in DPs from teeth treated with fibrinchitosan hydrogel. Immunolabeling analysis of the DP/hydrogel interface showed accumulation of neutrophil granulocytes in contact with both hydrogels $1 \mathrm{~d}$ after treatment. The DP close to this granulocyte area contained M2 but no M1 macrophages. These data collectively demonstrated that fibrin-chitosan hydrogels induced an inflammatory/immune response similar to that of the fibrin hydrogel. The results confirmed the potential clinical use of fibrin-chitosan hydrogel as a new scaffold for vital-pulp therapies.
\end{abstract}

Keywords: Chitosan, fibrin, hydrogel, inflammatory cells, M1 macrophage, M2 macrophage.

*Address for correspondence: Dr Alexis Gaudin, Department of Endodontics, University of Nantes, 1 place Alexis Ricordeau, Nantes, 44093 Nantes Cedex 01, France.

Telephone number: +33 649677083 Email: alexis.gaudin@univ-nantes.fr

Copyright policy: This article is distributed in accordance with Creative Commons Attribution Licence (http://creativecommons.org/licenses/by-sa/4.0/).

\begin{tabular}{|c|c|c|c|}
\hline & List of abbreviations & $\begin{array}{l}\text { APCs } \\
\text { Arg1 }\end{array}$ & $\begin{array}{l}\text { antigen-presenting cells } \\
\text { arginase } 1\end{array}$ \\
\hline$\alpha$-MEM & minimum essential medium alpha & $\mathrm{BSA}$ & bovine serum albumin \\
\hline
\end{tabular}




\begin{tabular}{|c|c|}
\hline CY & cyanine \\
\hline DA & degree of acetylation \\
\hline DAB & $\begin{array}{l}3,3^{\prime} \text { diaminobenzidine } \\
\text { tetrahydrochloride }\end{array}$ \\
\hline DC & dendritic cell \\
\hline $\mathrm{DP}$ & dental pulp \\
\hline ECM & extracellular matrix \\
\hline EDTA & ethylenediaminetetraacetic acid \\
\hline ELISA & $\begin{array}{l}\text { enzyme-linked immunosorbent } \\
\text { assay }\end{array}$ \\
\hline FACS & fluorescence-activated cell sorting \\
\hline $\mathrm{FH}$ & fibrin hydrogel \\
\hline $\mathrm{FCH}$ & fibrin-chitosan hydrogel \\
\hline FSC & forward scatter \\
\hline Iba1 & $\begin{array}{l}\text { ionised calcium binding adaptor } \\
\text { molecule } 1\end{array}$ \\
\hline $\operatorname{IgG}$ & immunoglobulin G \\
\hline IL & interleukin \\
\hline iNOS & inducible nitric oxide synthase \\
\hline LPS & lipopolysaccharide \\
\hline MHC & major histocompability complex \\
\hline MSC & mesenchymal stem cell \\
\hline MTA & mineral trioxide aggregate \\
\hline NGA & neutrophil granulocyte areas \\
\hline NK & natural killer \\
\hline qRT-PCR & $\begin{array}{l}\text { quantitative real-time polymerase } \\
\text { chain reaction }\end{array}$ \\
\hline RT & room temperature \\
\hline SSC & side scatter \\
\hline SEM & standard error of the mean \\
\hline TCR & $\mathrm{T}$ cell antigen receptor \\
\hline TBS & tris buffer saline \\
\hline Th & helper T \\
\hline TNF- $\alpha$ & tumour necrosis factor- $\alpha$ \\
\hline
\end{tabular}

\section{Introduction}

DP is responsible for tooth vitality and health as well as pain sensation, immune defence and repair/ regeneration upon dental injury. Bacterial invasion of dentineal tubules usually occurs when dentine is exposed following a breach in the integrity of the overlying enamel during accidental trauma, excessive wear or, most often, during caries (Farges et al., 2015). The DP is totally removed (pulpectomy) when DP inflammatory lesions (pulpitis) are suspected to be irreversible due to pain. Then, the emptied crown and root endodontic pulp space is sealed with a gutta percha-based inert material to prevent peri-dental bacterial colonisation. Recent studies have shown that pulpotomy is an attractive alternative to pulpectomy (Li et al., 2019).

Pulpotomy is a vital-pulp therapy in which the coronal DP is removed and the radicular DP tissue is preserved. Bioactive materials such as mineral trioxide aggregate, Biodentine ${ }^{\circledR}$ or calcium hydroxide cement are used as pulp-capping material to preserve the vitality of the pulpotomised DP. Placed in contact with the remaining amputated tissue, these materials induce DP cell differentiation events and are responsible for the formation of a scar tissue called tertiary dentine that objectifies the healing process (Simon et al., 2012). However, these materials do not restore the function of the coronal part of DP because there are no immune or nervous system components (Bjørndal et al., 2019; Li et al., 2019).

A therapeutic strategy to regenerate living DP-like tissue into the pulpotomised space may represent a more valuable approach. This strategy involves the implementation of a colonisable and biodegradable scaffold inducing a desired cellular behaviour, such as DP stem/progenitor cells migration from the preserved DP portion (Ducret et al., 2017; Galler et al., 2014; Luiz de Oliveira da Rosa et al., 2017; Yang et al., 2016). In this strategy, the scaffold is a key element for obtaining accurate DP regeneration. Numerous types of scaffold have been developed to reach this goal (Albuquerque et al., 2014; Colombo et al., 2014; Ducret et al., 2017). While there is no consensus on the ideal scaffold, the specifications include:

1. easy handling, for rapid implantation into the endodontic space by the dental practitioner (within minutes);

2. low viscosity, for a good injectability into a smallsized space;

3. antibacterial properties, to prevent the growth of residual endodontic bacteria that may hinder DP regeneration;

4. physiological degradation;

5. rapid replacement by stem/progenitor cells present in or penetrating into the scaffold and able to secrete an ECM similar to the DP tissue (Ducret et al., 2019; Moussa and Aparicio, 2019; Verma et al., 2017; Vishwanat et al., 2017).

An innovative chitosan-enriched fibrin hydrogel was recently developed that supports the formation of a DP-like connective tissue in vitro while efficiently inhibiting bacterial growth (Ducret et al., 2019). Comparisons with the fibrin-only counterpart indicated that chitosan does not impact upon the pro-regenerative properties of the fibrin hydrogel and promotes DP-mesenchymal stem cells' viability and migration as well as DP-like collagenous ECM deposition. These results suggested that fibrinchitosan-based hydrogels could be of interest in regenerative endodontic procedures (Aguilar et al., 2019). Another key property of hydrogels in the context of DP regeneration is that they should induce only a minor inflammatory response in the underlying amputated DP to prevent irreversible pulpitis or even tissue necrosis (Colombo et al., 2014). Although the addition of chitosan may improve a fibrin hydrogel, it is crucial to determine its effect on the inflammatory/immune response in the DP tissue before clinical use. The hypothesis tested in the present study was that the addition of chitosan within the fibrin hydrogel may induce a deleterious inflammatory/immune response in the DP tissue.

The aims of the study were to identify the molecular and cellular actors of the DP inflammatory/immune response to fibrin and fibrin-chitosan hydrogels in 
Table 1. Sequences of primer used.

\begin{tabular}{|c|c|c|c|}
\hline Primers & Forward $5^{\prime} \rightarrow 3^{\prime}$ & Reverse $5^{\prime} \rightarrow 3^{\prime}$ & $\begin{array}{l}\text { Product size } \\
\text { (base pairs) }\end{array}$ \\
\hline HPRT & CCTTGGTCAAGCAGTACAGCC & TTCGCTGATGACACAAACATGA & 188 \\
\hline Il6 & ACAGCGATGATGCACTGTCA & GGAACTCCAGAAGACCAGAGC & 129 \\
\hline Il10 & CCTCTGGATACAGCTGCGAC & GTAGATGCCGGGTGGTTCAA & 157 \\
\hline $\operatorname{Tnf}$ & TGGGCTCCCTCTCATCAGTT & TGGTGGTTTGCTACGACGTG & 102 \\
\hline Il1b & TGACTCGTGGGATGATGACG & TGTCGTTGCTTGTCTCTCCT & 200 \\
\hline Ccl2 & СТССАССАСТАTGCAGGTCTC & GGGCATTAACTGCATCTGGC & 101 \\
\hline iNos & GCATTCAGATCCCGAAACGC & GTGAACACGTTCTTGGCGTG & 130 \\
\hline Arg1 & GTGGCGTTGACCTTGTCTTG & GCCTGGTTCTGTTCGGTTTG & 144 \\
\hline
\end{tabular}

an in vivo model of rat incisor pulpotomy and to decipher the M1/M2 polarisation of macrophages - a condition primordial for DP healing after hydrogel implantation.

\section{Materials and Methods}

\section{Fibrin-alone and fibrin-chitosan formulations}

Fibrin-alone and fibrin-chitosan formulations were prepared as previously detailed by mixing $\alpha$-MEM medium (M4526, Sigma-Aldrich), 80 mg/mL human fibrinogen (F3879, Sigma-Aldrich), 3 mol/L sodium chloride, $0.4 \mathrm{~mol} / \mathrm{L}$ calcium chloride, phosphatebuffered saline without calcium (for fibrin-alone hydrogels) or $1 \%$ chitosan solution (for fibrin-chitosan hydrogels) and $4 \mathrm{U} / \mathrm{mL}$ thrombin (T6884, SigmaAldrich) in appropriate proportions to get a final concentration of $10 \mathrm{mg} / \mathrm{mL}$ fibrin and $0.5 \%$ chitosan in the hydrogel (Ducret et al., 2019). The shrimp-shell chitosan was purchased from Mahtani Chitosan ${ }^{\circledR}$ Veraval, Gujarat, India (batch type 243, molar mass $160 \pm 10 \mathrm{~kg} / \mathrm{mol}$, dispersity index $1.9 \pm 0.2)$. The sample was reacetylated before use until the DA was $40 \%$. After preparation of the chitosan solution, its $\mathrm{pH}$ was increased to a cytocompatible level (7.1-7.2) and the final solution was sterilised by autoclaving it for $20 \mathrm{~min}$ at $121^{\circ} \mathrm{C}$ before mixing it with the other components under sterile conditions.

\section{Rat incisor pulpotomy experimental model}

26 female Sprague-Dawley rats weighing 200-250 g were used throughout the study. Rat experiments were carried out in strict accordance with a protocol approved by the Committee on the Ethics of Animal Experiments of Pays de la Loire. Pulpotomies were performed as previously described (Kawanishi et al., 2004; Renard et al., 2016) under general anaesthesia using an intramuscular injection of xylazine $(8 \mathrm{mg} /$ $\mathrm{kg}$ ) and ketamine $(805 \mathrm{mg} / \mathrm{kg})$; a periapical injection of $0.1 \mathrm{~mL}$ articaine was used for local anaesthesia. Coronal portions exposed to the oral cavity of the upper incisors were removed horizontally using a round tungsten steel bur to expose the pulp at the pulp horn. The entrance of the pulp horn was enlarged using endodontic files to a length of $5 \mathrm{~mm}$, to create sufficient space in which the fibrin or the fibrin-chitosan formulation could be deposited. $5 \mu \mathrm{L}$ of the injectable formulation were dropped into the cavities and left for $10 \mathrm{~min}$ at RT for gelation. Then, cavities were sealed with a calcium-silicate-based restorative cement (Biodentine ${ }^{\circledR}$, Septodont, Saint Maur des Fossés, France). Animals were sacrificed by $\mathrm{CO}_{2}$ inhalation $3 \mathrm{~h}$ or $1 \mathrm{~d}$ after cement setting. Next, the incisors were extracted.

\section{Total RNA extraction and qRT-PCR}

A qRT-PCR analysis was performed on the DP of teeth extracted $3 \mathrm{~h}$ after the implantation of fibrin and fibrin-chitosan hydrogel formulations. 12 upper incisors from 6 rats were used for each condition (fibrin, fibrin-chitosan). Healthy maxillary incisors were used as a control. The incisors were split longitudinally into two halves and the pulp tissues were carefully removed using a sterile $\mathrm{K}$ file (Dentsply Maillefer, Ballaigues, Switzerland). Total RNA was extracted using an RNeasy Mini Kit (Qiagen) according to the manufacturer's instructions. For cDNA synthesis, $1 \mu \mathrm{g}$ of total RNA was used as a template for reverse transcription with a High-Capacity cDNA Reverse Transcription Kit (Invitrogen). PCR was performed in a Viia7 ${ }^{\mathrm{TM}}$ Real Time PCR System (Thermo Fisher Scientific) with a Fast SYBR Green qPCR Master Mix (Life Technologies). Primer sequences are listed in Table 1. The transcript expression level was defined as a foldchange of the mRNA level in a given sample relative to the calibrator level. The DP of untreated teeth was used as a calibrator, this defined the $1 \times$ expression of each gene, and the mRNA expression level was calculated as $2^{-\Delta \Delta \mathrm{Ct}}$ where $\Delta \Delta \mathrm{Ct}=(\mathrm{Ct}$ Target $-\mathrm{Ct} H P R T)$ sample - (CtTarget - CtHPRT) calibrator.

\section{Flow cytometry}

Flow cytometry was performed as previously described. Briefly, the DP of 8 incisors from 4 rats 
Table 2. Antibodies used.

\begin{tabular}{|c|c|c|c|c|c|c|c|}
\hline Specificity & Clone & Supplier & Reference & Fluorochrome & Dilution & Species & \\
\hline CD45 & Ox1 & $\mathrm{BD}$ & 561586 & APC cy7 & $1: 200$ & Mouse & Monoclonal \\
\hline Ig $\kappa$-chain & Ox12 & _ & _ & A647 & $1: 500$ & Mouse & Monoclonal \\
\hline TCR- $\alpha \beta$ & R7 3 & $\mathrm{BD}$ & 557019 & PERCP & $1: 200$ & Mouse & Monoclonal \\
\hline CD4 & Ox.35 & $\mathrm{BD}$ & 561578 & PEcy7 & $1: 1,000$ & Mouse & Monoclonal \\
\hline $\begin{array}{c}\text { CD161 } \\
\text { (NKRP1) }\end{array}$ & 03.02 .2003 & - & - & Alexa 647 & $1: 1,000$ & Mouse & Monoclonal \\
\hline Granulocyte & RP-1 & $\mathrm{BD}$ & 550002 & PE & $1: 200$ & Mouse & Monoclonal \\
\hline $\begin{array}{c}\text { MHC class } \\
\text { II }\end{array}$ & OX-6 & $\mathrm{BD}$ & 557016 & PERCP & $1: 500$ & Mouse & Monoclonal \\
\hline CD103 & OX62 & _ & _ & A647 & $1: 2,500$ & Mouse & Monoclonal \\
\hline CD11b & WT.5 & $\mathrm{BD}$ & 562108 & V450 & $1: 200$ & Mouse & Monoclonal \\
\hline CD68 & ED1 & Biorad & MCA341R & _ & $1: 50$ & Mouse & Monoclonal \\
\hline Iba-1 & _- & Abcam & ab5076 & - & $1: 2,000$ & Goat & Polyclonal \\
\hline CD163 & EPR19518 & Abcam & ab182422 & - & $1: 400$ & Rabbit & Monoclonal \\
\hline iNOS & _ & Abcam & ab15323 & _ & $1: 50$ & Rabbit & Polyclonal \\
\hline $\begin{array}{c}\text { Neutrophil } \\
\text { elastase }\end{array}$ & - & Abcam & $a b 68672$ & - & $1: 200$ & Rabbit & Polyclonal \\
\hline IgG & - & $\begin{array}{c}\text { Jackson } \\
\text { ImmunoResearch }\end{array}$ & $715-605-150$ & Alexa 647 & $1: 500$ & Mouse & Polyclonal \\
\hline IgG & - & $\begin{array}{c}\text { Jackson } \\
\text { ImmunoResearch }\end{array}$ & $711-545-152$ & Alexa 488 & $1: 500$ & Rabbit & Polyclonal \\
\hline IgG & - & $\begin{array}{c}\text { Jackson } \\
\text { ImmunoResearch }\end{array}$ & 705-065-147 & - & $1: 500$ & Goat & Polyclonal \\
\hline
\end{tabular}

(for each condition) was minced into $0.5 \mathrm{~mm}^{3}$ fragments and centrifuged. The tissue was digested in $2.5 \mathrm{mg} / \mathrm{mL}$ collagenase D (Roche) and incubated at $37^{\circ} \mathrm{C}$. Digestion was stopped after $45 \mathrm{~min}$ with 2 mM EDTA. Then, DP cells were washed twice with PBS supplemented with $2 \%$ foetal calf serum and $2 \mathrm{mmol} / \mathrm{L}$ EDTA. The cell suspension was filtered through a $100 \mu \mathrm{m}$ nylon filter to obtain a single cell suspension. In the untreated condition, the pulp of the two upper incisors was pooled to obtain $1 \times 10^{9}$ cells. Next, $1 \times 10^{9}$ cells were incubated with the viability dye eF506 (Thermo Fisher Scientific) and stained with fluorescent antibodies (Table 2). Then, cells were counted with a FACS Canto II (BD Biosciences) and the results were analysed using FlowJo software (TreeStar Inc., Ashland, NC, USA). All results are based on the same initial gating strategy (Fig. 2a). Cells were selected according to their size (FSC) and granularity (SSC) and non-viable cells were excluded using a viability dye.

Immunohistochemistry and immunofluorescence Immunohistochemistry was performed to detect neutrophil elastase, iNOS and CD163. For each DP condition (untreated teeth, teeth treated with fibrin or fibrin-chitosan hydrogels), four teeth from two rats were fixed in formalin solution at $4{ }^{\circ} \mathrm{C}$ overnight, decalcified in $4 \%$ EDTA at $50{ }^{\circ} \mathrm{C}$ in a $\mathrm{KOS}$ microwave (Milestone, Kalamazoo, MI, USA) for up to $10 \mathrm{~d}$, embedded in paraffin wax and cut into $3 \mu \mathrm{m}$-thick sections. Sections in which the hydrogel/ DP interface was observable were rehydrated and, then, heat-induced epitope retrieval was performed in Tris-EDTA buffer $(10 \mathrm{mmol} / \mathrm{L}$ Tris base, $1 \mathrm{mmol} / \mathrm{L}$ EDTA solution, $0.05 \%$ Tween 20, pH 9.0) for $20 \mathrm{~h}$ at $60{ }^{\circ} \mathrm{C}$. Sections were incubated with $3 \%$ hydrogen peroxide for $15 \mathrm{~min}$ at $\mathrm{RT}$ to block endogenous peroxidase activity. Then, sections were treated with blocking buffer (2\% normal donkey serum, $1 \%$ BSA) in TBS-0.05\% Tween-20 for 25 min at RT and incubated for $1 \mathrm{~h}$ at RT with the appropriate primary antibody (Table 2). After washing with TBSTween-20, sections were sequentially incubated with a biotin-conjugated donkey anti-rabbit secondary IgG (Jackson ImmunoResearch). Next, sections were developed using horseradish-peroxidaseconjugated streptavidin (Agilent Technologies) and DAB substrate solution (MM France, Brignais, France). Counterstaining was performed using Gill 2 haematoxylin (Sigma-Aldrich). Sections were finally dehydrated, cleared in Ottix Plus (MM France, Brignais, France) and mounted under a coverslip using Pertex (MM France).

Triple sequential immunofluorescence staining was performed to identify M1 and M2 macrophages in the DP samples. Sections were prepared as described above (except peroxidase activity blocking with $3 \%$ hydrogen peroxide) and incubated at RT for $1 \mathrm{~h}$ with mouse anti-CD68, goat anti-Iba1, rabbit anti-CD163 or rabbit anti-iNOS (Table 2). Immunodetection was performed using Jackson ImmunoResearch secondary antibodies and a fluorescent-conjugated streptavidin reactive. An Alexa Fluor-647 donkey anti-mouse IgG was used to detect CD68 and an 
Alexa Fluor-488 donkey anti-rabbit IgG was used to detect CD163 and iNOS. For Iba1, detection was performed with a biotin-SP donkey anti-goat IgG antibody amplified with CY3-coupled streptavidin. Finally, the sections were thoroughly washed in PBS, counterstained with DAPI and mounted using ProLong Gold antifade reagent (Fisher Scientific). Negative controls were performed by omitting primary antibodies. Finally, the slides were digitised using a Nanozoomer (Hamamatsu Photonics, Hamamatsu, Japan) and observed using an NDP. view virtual microscope (Hamamatsu Photonics).

\section{Statistical analysis}

Statistical analysis was performed using GraphPad Prism software. The results were expressed as mean \pm SEM. Group comparisons were performed using a Mann-Whitney's unpaired U test. $p<0.05$ was considered statistically significant.

\section{Results}

Gene expression of pro- and anti-inflammatory markers

To characterise the early DP inflammatory/immune response induced by fibrin and fibrin-chitosan hydrogels, IL-6, TNF- $\alpha, I L-1 \beta, C C L-2, I L-10$ and Arg1
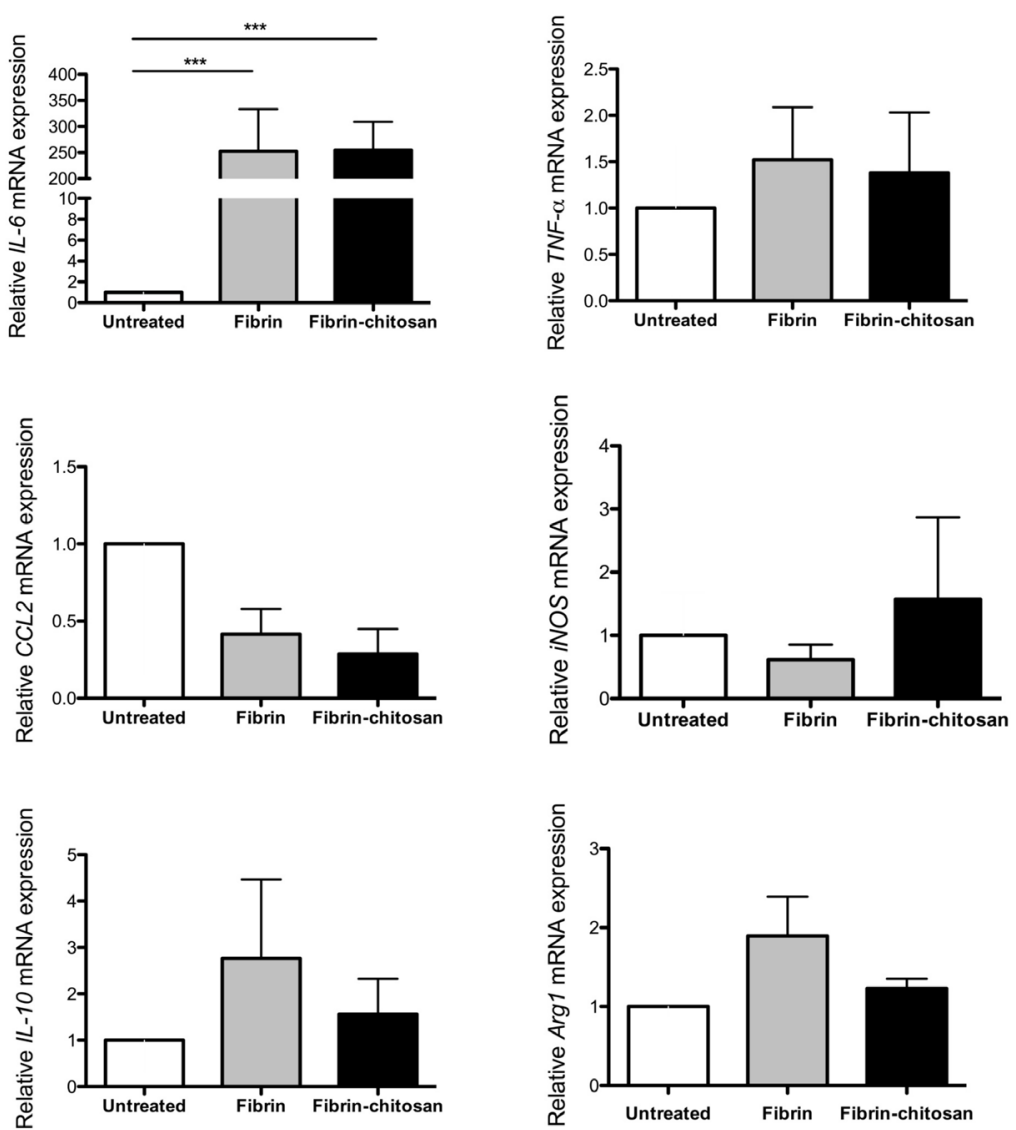

expressions were assessed by qRT-PCR $3 \mathrm{~h}$ after fibrin and fibrin-chitosan formulations' implantation and compared with gene expression in the DP of untreated teeth (Fig. 1). Both types of hydrogels induced a significant and strong increase in IL-6 expression versus untreated samples $(p<0.0001)$. There were no statistically significant differences between the two types of hydrogels. The expression of the other genes tested was not significantly modified.

\section{Immune cell quantification $1 \mathrm{~d}$ after hydrogel implantation}

To assess fibrin and fibrin-chitosan effects on the recruitment of inflammatory/immune cells, these cells were quantified in the amputated DP by FACS analysis $1 \mathrm{~d}$ after hydrogel implantation and results were compared with untreated incisors (Fig. 2). In the viable DP cell population, the percentage of leukocytes $\left(\mathrm{CD} 45^{+}\right)$was not significantly different in untreated teeth or after fibrin or fibrin-chitosan hydrogel implantation $(0.9 \pm 0.2 \%, 0.5 \pm 0.1 \%$ and $0.7 \pm 0.1 \%$, respectively) (Fig. 2a). Then, the different leukocyte sub-populations present in the DP were quantified for each condition (Fig. 2b). When gated on the leukocytes, a significantly larger proportion of neutrophil granulocytes was observed in the DP of hydrogel-treated teeth as compared to the DP of untreated teeth $[14 \pm 2.7 \%$ in untreated teeth;

Fig. 1. Analysis of $I L-6, I L-1 \beta, T N F-\alpha, I L-10, i N O S, A r g 1$ and $C C L 2$ transcripts by qRT-PCR $3 \mathrm{~h}$ after pulpotomy and fibrin or fibrin-chitosan hydrogel implantation. Each graph represents the relative expression levels of each gene to HPRT (mean \pm SEM) in the pulp of fibrin- and fibrin-chitosan-treated teeth when compared to the pulp of untreated teeth. The latter was used to define the 1-fold expression of each gene $(n=6) .{ }^{* * *} p<0.0001$ (Mann-Whitney $\mathrm{U}$ test). 
a
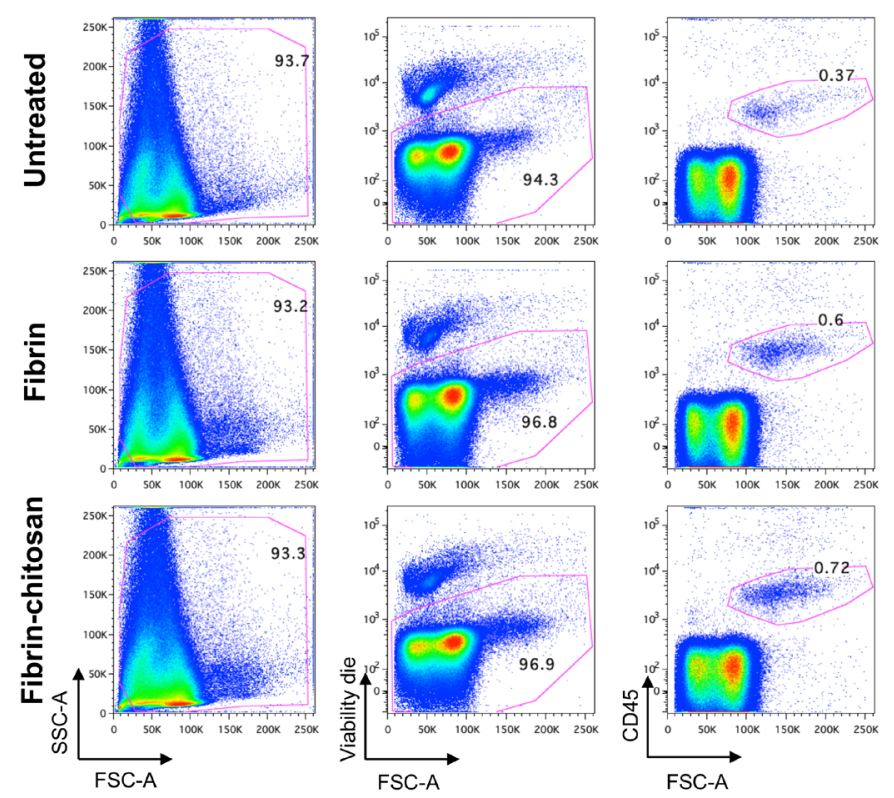

b
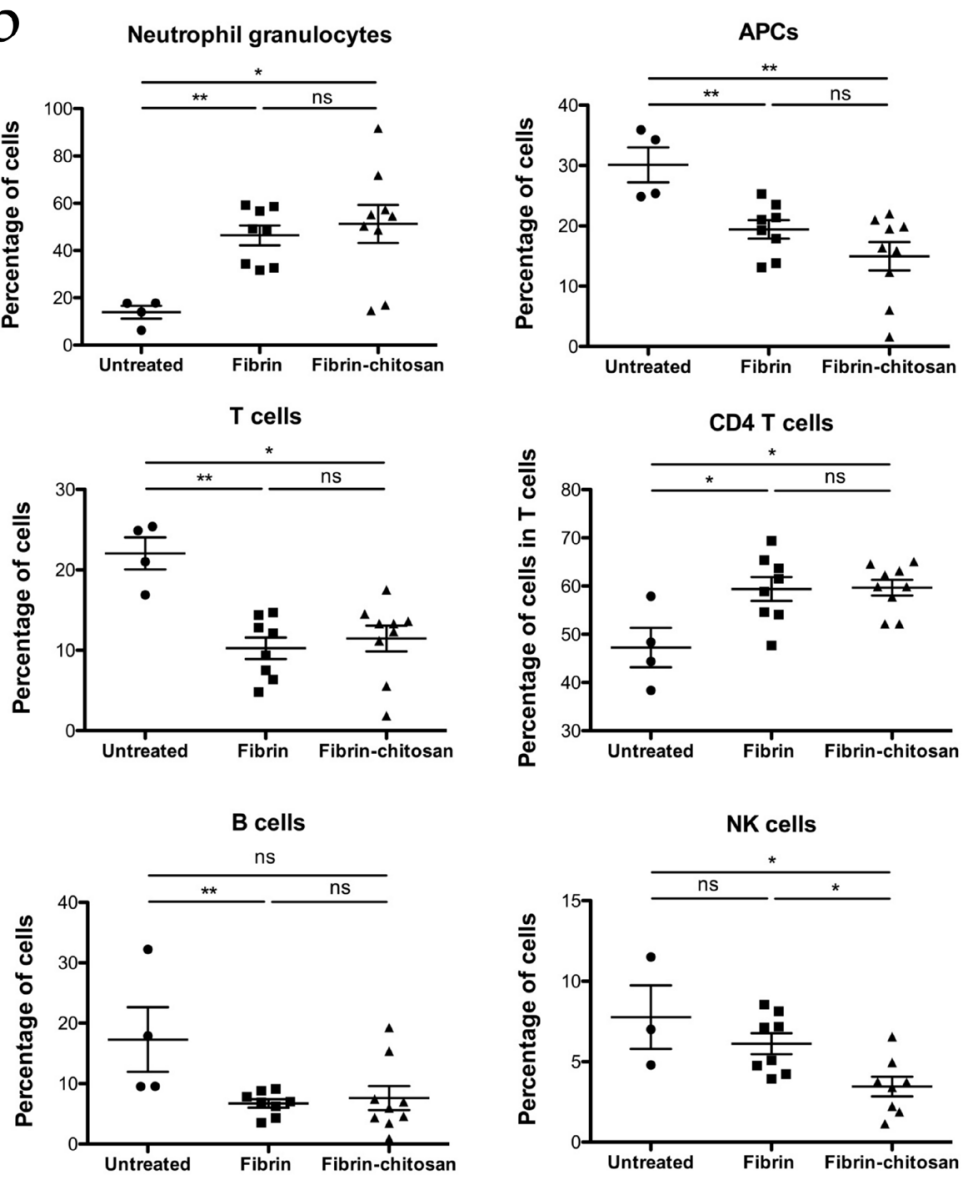
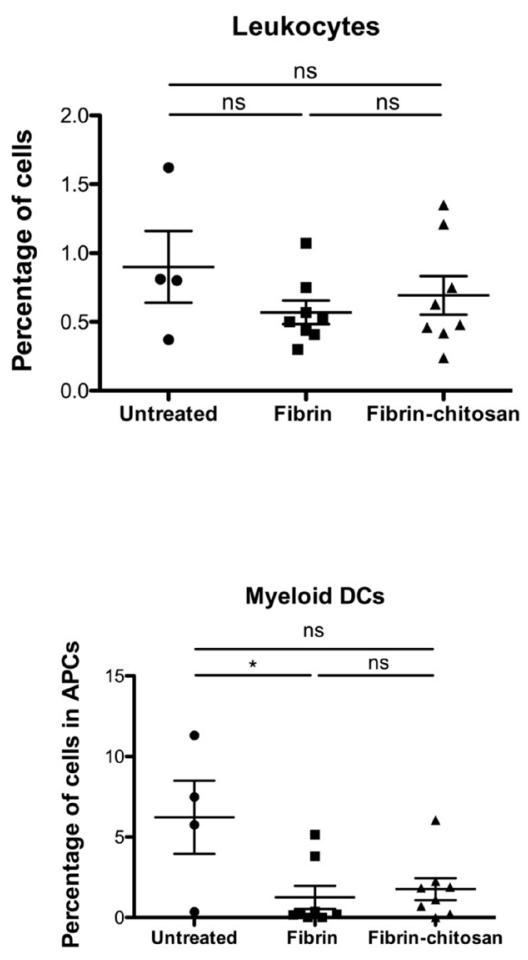

Fig. 2. FACS analysis of leukocytes $\left(\mathrm{CD}^{+} 5^{+}\right)$in the pulp $1 \mathrm{~d}$ after fibrin or fibrin-chitosan hydrogel implantation when compared to the pulp of untreated teeth. Dead cells were eliminated using a viability dye. (a) Representative FACS dot plots are shown for each condition. The graph shows the mean \pm SEM from two independent experiments, each point corresponding to one pulp's incisor $(n=8)$. For untreated teeth, the pulp cells from the two incisors of each animal were pooled $(n=4)$. (b) Percentages of cells expressing specific markers for neutrophil granulocytes (granulocyte ${ }^{+}$), APCs (MHC class $\left.\mathrm{II}^{+}\right), \mathrm{T}$ cells $\left(\mathrm{TCR}-\alpha \beta^{+}\right), \mathrm{B}$ cells (IgK-chain ${ }^{+}$), and NK cells (CD161 ${ }^{\text {high }}$ ) gated in the living leukocyte population. For $\mathrm{CD} 4^{+} \mathrm{T}$ cells, cells were gated in the T cell population, and for myeloid DCs $\left(\mathrm{CD} 103^{+} \mathrm{CD} 11 \mathrm{~b}^{+}\right)$, cells were gated in the APC population. ${ }^{*} p<0.05,{ }^{* *} p<0.001$ (Mann-Whitney U test). ns: not significant. 
$46.4 \pm 4.1 \%(p=0.004)$ and $51.3 \pm 8 \%(p=0.03)$ in fibrin- and fibrin-chitosan-treated teeth, respectively]. Conversely, compared to the untreated teeth, the leukocyte population had a significant decrease in APCs (MHC class $\mathrm{II}^{+}$) in fibrin and fibrin-chitosantreated teeth $[30.1 \pm 2.9 \%$ in untreated teeth; $19.4 \pm 1.5 \%(p=0.008)$ and $14.9 \pm 2.3 \%(p=0.003)$ in fibrin and fibrin-chitosan-treated teeth, respectively].

In the APC population, the percentage of myeloid DCs $\left(\mathrm{CD}_{103}{ }^{+} \mathrm{CD}_{11 b^{+}}\right)$was significantly lower $(p=0.03)$ in fibrin-treated teeth $(1.2 \pm 0.7 \%)$ as compared to untreated teeth $(6.2 \pm 2.3 \%)$ whereas fibrin-chitosan treatment did not modify the proportion of this cell population. Regarding lymphocytes, the $\mathrm{T}$ cell population $\left(\mathrm{TCR}-\alpha \beta^{+}\right.$) was significantly reduced within the leukocyte population in both hydrogel samples (fibrin $5.9 \pm 0.6 \%$, fibrinchitosan $6.8 \pm 1 \%$ ) when compared to untreated teeth $(10.5 \pm 1.5 \%)(p=0.01$ and $p=0.004$, respectively). Within the $\mathrm{T}$ cell population, a significant increase in $\mathrm{CD}^{+}$cells was observed $(47.2 \pm 4.1 \%$ in untreated teeth versus $59.4 \pm 2.5 \%$ in fibrin-treated samples and $59.7 \pm 1.6 \%$ in fibrin-chitosan ones; $p=0.048$ and $p=0.025$, respectively). The percentage of $\mathrm{B}$ cells (IgK-chain ${ }^{+}$) was significantly lower in fibrin samples $(6.7 \pm 0.7 \%)$ when compared to untreated DP $(17.3 \pm 5.3 \% ; p=0.004)$. Finally, the percentage of NK cells (CD161 ${ }^{\text {high }}$ ) was significantly decreased in fibrin/chitosan-treated teeth $(3.4 \pm 0.6 \%$, compared to $7.7 \pm 1.9 \%$ in untreated teeth, $p=0.048$ ) but not in fibrin-treated teeth.

Localisation of neutrophil granulocytes and identification of alternatively activated macrophages (M2) at the hydrogel/DP interface

Immunohistochemistry was performed $1 \mathrm{~d}$ after hydrogel implantation to characterise and localise inflammatory/immune cells close to fibrin and fibrinchitosan hydrogels (Fig. 3). NGA were identified by staining neutrophil-elastase ${ }^{+}$cells in close contact with both types of hydrogels (Fig. 3a,b). iNOS was immunolocalised in NGA, with no difference between hydrogels (Fig. 3c,d). Then, next step was to identify classically activated macrophages (M1) coexpressing iNOS, CD68 and/or Iba1. M1 macrophages $\left(\mathrm{iNOS}^{+} \mathrm{CD}^{+} 8^{+}\right.$or $\mathrm{iNOS}^{+} \mathrm{Iba}^{+}$) were not detected in the NGA close to the hydrogel implantation zone (Fig. 3g,k,h,l). In contrast, CD163, a marker of M2 macrophages that was observed in the DP area close to the NGA (Fig. 3e,f), was clearly co-expressed with CD68 (Fig. 3i,j) and Iba1 (Fig. 3m,n) in both experimental conditions. The presence of chitosan within the fibrin hydrogel did not modify the localisation of these M2 macrophages.

\section{Discussion}

In the context of DP tissue engineering, hydrogel scaffolds must exhibit biocompatibility, biodegradability and antimicrobial activities against microorganisms present along the dentine wall and/ or in the dentine tubules (Verma et al., 2017). For DP regeneration after pulpotomy, hydrogels should also not induce or induce only a low inflammatory response in the underlying amputated DP to prevent irreversible pulpitis or even necrosis of the remaining tissue (Colombo et al., 2014; Giraud et al., 2019; Morotomi et al., 2015; Morotomi et al., 2019; Shah et al., 2020). Recently, Ducret et al. (2019) have designed and characterised cellularisable hydrogels composed either of fibrin alone or fibrin and chitosan. Both hydrogel types stimulate DP tissue neoformation in vitro by promoting DP-MSC viability and spreading as well as DP-like collagenous ECM deposition. In addition, the fibrin-chitosan hydrogel efficiently inhibits bacterial growth, suggesting that the use of this hydrogel could be relevant for regenerative endodontic procedures. The hydrogel does not impair the DP regeneration process by triggering early deleterious inflammatory events (Ducret et al., 2019).

Fibrin implantation induced an up-regulation of IL-6 mRNA when compared to the healthy untreated DP, whereas other cytokines, chemokines and enzymes tested, either pro- or anti-inflammatory, remained unchanged. The presence of chitosan within the fibrin hydrogel did not modify this DP inflammatory/immune response. IL-6 is a pleiotropic cytokine produced by a variety of immune and non-immune cells (macrophages, neutrophils, keratinocytes, fibroblasts, endothelial cells, odontoblasts) (Farges et al., 2011; Matsuki and Yamamoto, 1992) in response to stimuli such as infection and trauma. IL-6 regulates many aspects of the local immune response (Langub et al., 1996) and has been found in inflamed pulp tissue and periapical lesions (Azuma et al., 2014; Čolić et al., 2009; Wisithphrom et al., 2006). Therefore, the up-regulation of IL- 6 mRNA was expected after the pulpotomy because of the mechanical injury (Kawashima et al., 2005; Renard et al., 2016). This suggests that most of the inflammatory response observed was related to the mechanical preparation of the tooth and not to the nature of the implanted material. Finally, this upregulation of $I L-6 \mathrm{mRNA}$ was comparable to the weak to moderate IL-6 expression localised at the cervical radicular third at $48 \mathrm{~h}$ detected in odontoblasts and inflammatory cells after pulpotomy of rat molars with MTA (Lopes et al., 2019).

iNOS expression was not modified by the hydrogels. Although not statistically significant, CCL2 expression showed a tendency to decrease. This tendency was surprising, because CCL2 is a pro-inflammatory mediator promoting infiltration of monocytes and differentiation in M1-polarised macrophages (Sierra-Filardi et al., 2014). Fibrin is naturally involved in homeostasis and wound healing and can regulate inflammation. However, Hsieh et al. (2017) reported that fibrin can inhibit the release of CCL2 and that $i N O S$ expression is inhibited by macrophages after treatment with fibrinogen in 

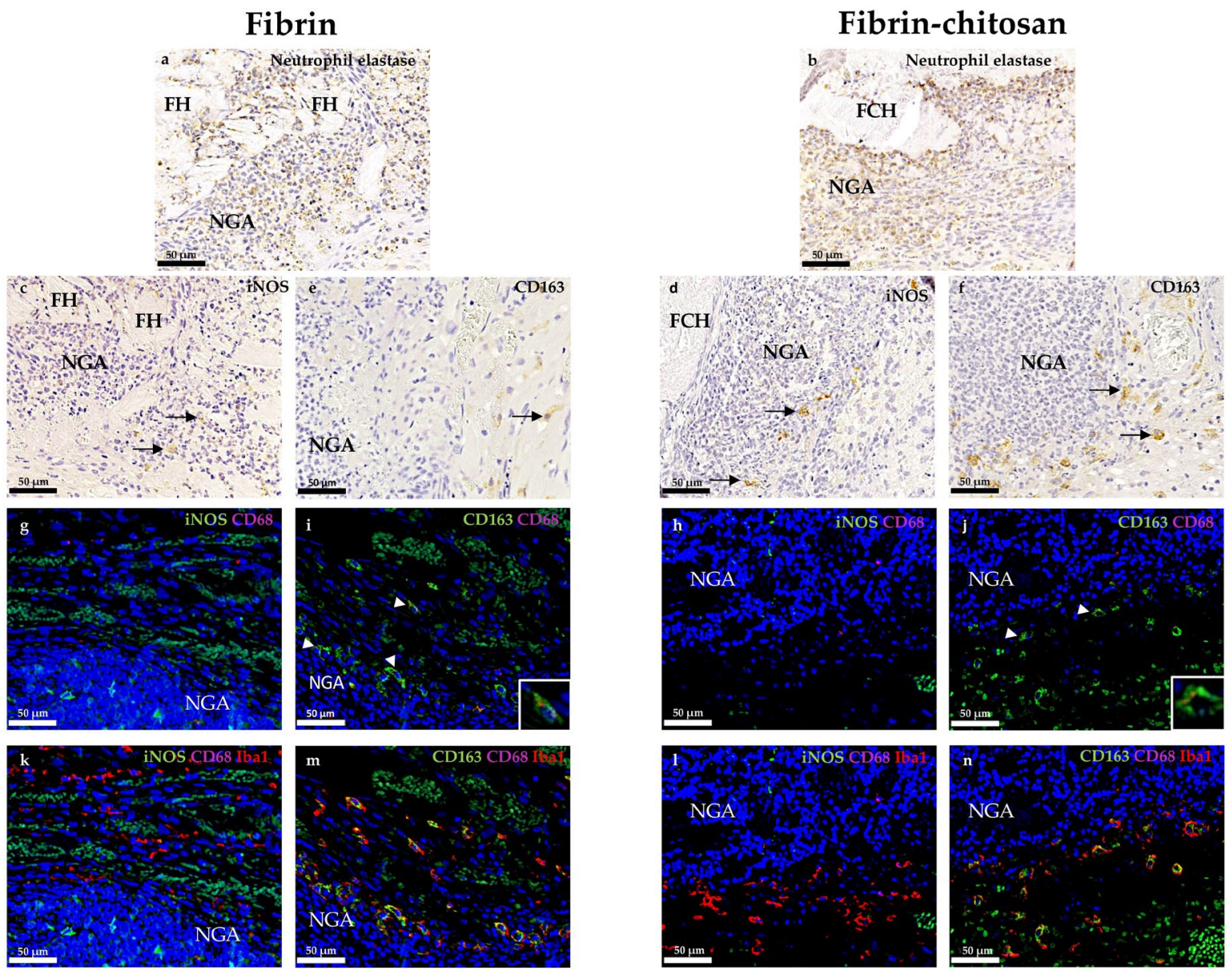

Fig. 3. Characterisation of immune cells at the pulp/hydrogel interface $1 \mathrm{~d}$ after fibrin $(\mathrm{a}, \mathrm{c}, \mathrm{e}, \mathrm{g}, \mathbf{i}, \mathbf{k}, \mathrm{m})$ or fibrin/chitosan (b,d,f,h, $\mathbf{j}, \mathbf{l}, \mathbf{n})$ hydrogel implantation. Immunolocalisation of $(\mathbf{a}, \mathbf{b})$ neutrophil elastase, (c,d) iNOS and (e,f) CD163. Arrows show positive cells. M1 and M2 macrophages were identified using triple immunofluorescent staining. Rat pulp sections were stained with $(\mathbf{g}, \mathbf{h}, \mathbf{k}, \mathbf{l})$ anti-iNOS (green), anti-CD68 (magenta), anti-Iba-1 (red) and DAPI (blue) or with (i,j, $\mathbf{j}, \mathbf{n})$ anti-CD163 (green), anti-CD68 (magenta), anti-Iba-1 (red) and DAPI (blue). (m,n) CD163 ${ }^{+} \mathrm{CD}^{+} 8^{+}$cells are shown by arrowheads. $\mathrm{CD} 163^{+} \mathrm{CD}^{2} 8^{+} \mathrm{Iba1} 1^{+}$ cells appeared yellow on the merge. Cell nuclei were stained in blue. NGA: neutrophil granulocyte area; FH: fibrin hydrogel; FCH: fibrin-chitosan hydrogel. Insert: high magnification of stained cells.

vitro. Thus, fibrin could decrease the expression of these pro-inflammatory genes that were enhanced during DP injury at the moment of pulpotomy.

Previous studies have demonstrated that 3D porous chitosan scaffolds in contact with a living tissue up-regulate the expression of pro-inflammatory cytokines or influence the resolution of inflammation according to their DA. Vasconcelos et al. (2013) showed that a $15 \%$ DA is pro-inflammatory and induces more IL-6 secretion than a $5 \%$ DA chitosan scaffold, which induces an anti-inflammatory response. More recently, Chedly et al. (2017) have shown that the implantation of chitosan hydrogels (DA $=4 \%$ ) into rat spinal cord immediately after a bilateral dorsal hemi-section induces an M2 macrophage polarisation that can be related to nerve tissue regeneration and functional recovery. In the same work, the implantation of a high DA chitosan hydrogel (DA $=38 \%$ ) failed to promote tissue regeneration and resulted in a much higher inflammation. In a study by Ducret et al. (2019), the DA of the chitosan used in association with fibrin was
$40 \%$. Solutions of chitosan with a lower DA could not be brought to $\mathrm{pH}$ neutrality without forming precipitates. The presence of chitosan within the fibrin hydrogel did not modify the up-regulation of IL-6 expression observed with fibrin alone. This could be because direct contact of chitosan with the tissue was limited due to the presence of the fibrin network.

Although rodent molars are frequently used to assess pulpal inflammation due to their anatomical similarities to human permanent tooth, rat incisors were chosen in the present study as an experimental model for pulpotomy. Rat incisors markedly differ from molars because they are continuously erupting teeth. There is no closed root apex and the regenerative properties, including the crosstalk between immune cells and DP stem cells, likely differ dramatically from that in the molar pulp. However, rat incisors have been used for a long time and are considered as a valuable experimental model for the assessment of the DP inflammatory/immune response to biomaterials or molecules proposed for DP engineering (Kawashima et al., 2005; Obersztyn 
and Jedrzejczyk, 1968; Xu et al., 2019; Zheng et al., 2009). This experimental model offers several advantages over rat molars, such as ease of use and standardisation (Zheng et al., 2009). The volume of the canal also allows for obtaining enough space for the application of hydrogels. Finally, this approach can provide adequate cell amounts to identify specific sub-populations of immune cells by FACS (Renard et al., 2016). FACS analysis using rat incisors may also help to explain which cells are releasing the factors that attract immune cells. Such experiments would not be possible using molars.

In the present study, cytokine network analysis was performed using qRT-PCR at $3 \mathrm{~h}$, while cellular changes were evaluated using FACS and immunostaining $24 \mathrm{~h}$ after hydrogel implantation. The inflammatory response of the DP begins with the release of measurable inflammatory mediators, such as the cytokine network produced by resident cells (odontoblasts and resident immune cell) (Farges et al., 2011; Gaudin et al., 2015; Rechenberg et al., 2016). Regarding the cytokine network, $3 \mathrm{~h}$ was elicited as a preferential time point since proinflammatory cytokines (IL- 6, IL1- $\beta$, TNF- $\alpha$ ) and chemokines (CXCL1, CXCL2, CCL2) as well as iNOS peaked after $3 \mathrm{~h}$ in response to lipopolysaccharide injury and decreased thereafter similar to inflammation in rats (Renard et al., 2016). Infiltration of macrophages in response to LPS has been reported to peak after 9 h (Kawanishi et al., 2004; Takimoto et al., 2014). Leukocytes in general and specific subsets such as granulocytes, DCs, NK, B and T cells increase after $9 \mathrm{~h}$ upon LPS stimulation and decrease to come back to baseline after $3 \mathrm{~d}$ (Renard et al., 2016). Although stimulation with LPS exhibits different mechanisms of action from fibrin or chitosan, the effects on similar target cells was expected to be in a similar kinetic range. However, further experiments are required to understand and analyse the fine tuning of the immune response of the DP to biomaterials especially with the new concept of partial regeneration by such hydrogels.

Although calcium silicate cements were not in direct contact with the DP, it is not possible to exclude that they did not affect the inflammatory process. Nevertheless, this same procedure was used in the two experimental groups. Calcium silicate cements (MTA and its derivative or Biodentine ${ }^{\circledR}$ ) affect the inflammatory process when in direct or indirect (because of released components) contact with pulp tissues (Braga et al., 2014; Ito et al., 2014; Kunert and Lukomska-Szymanska, 2020; Modena et al., 2009; Yeh et al., 2018; Zhu et al., 2017). Biodentine ${ }^{\circledR}$ was used in the present study because this biomaterial would be the one used in humans. Biodentine ${ }^{\circledR}$ is regularly used for vital-pulp therapy (pulp capping and pulpotomy) and also as a dentine substitute (Brizuela et al., 2017; Nowicka et al., 2013; Parirokh et al., 2018; Tran et al., 2012). Moreover, the sealing ability, the setting time and the handling properties of the Biodentine ${ }^{\circledR}$ have been assessed in vitro and in vivo and are compatible with the present study experimental design (Camilleri et al., 2013; 2014).

In the present study, fibrin or fibrin-chitosan hydrogel implantation did not induce an increase in total leukocytes within the DP remaining after pulpotomy but did increase the proportion of neutrophil granulocytes in the leukocyte population. Neutrophil granulocytes represent $14 \%$ of the leukocytes in the DP of untreated teeth and reached around $50 \%$ of leukocytes after pulpotomy and hydrogel implantation. These data were confirmed by immunolabeling, which showed an accumulation of neutrophils close to the fibrin hydrogel forming an NGA. Chitosan did not modify this non-specific immune response. Previous studies have shown that DCs are initially recruited in the injured DP to destroy invading microorganisms (Colombo et al., 2014; Farges et al., 2015). Within the APC population, myeloid DCs (also called conventional DCs) are able to phagocytise bacteria and activate $\mathrm{T}$ cells, thus inducing an antigen-specific immune response. The present study showed that the fibrin hydrogel induced a decrease in the proportion of myeloid DCs while the fibrin-chitosan hydrogel had no significant effect on the proportion of these cells across the whole APC population. It was further observed that within the T cell population, both types of hydrogels equally increased the proportion of $\mathrm{CD}^{+}$cells. In the DP, as in other tissues, Th1, Th2 or Th17 subsets of the CD4 ${ }^{+}$ $\mathrm{T}$ lymphocytes undertake specific immune functions that include the regulation of inflammation (Farges et al., 2015). It would be interesting to identify the $T$ cell affiliation of these specific subsets in response to the hydrogels. The accumulation of NK cells, a wellknown arm of the innate immune response (Scott and Trinchieri, 1995), is enhanced by chitosan in a model of Herpes-Simplex-Virus-infected mice (Choi et al., 2016). The present study data were not consistent with the result of Choi et al. (2016) because chitosan induced a significant decrease in the proportion of NK in the leukocyte population when compared to untreated teeth. This is probably due to a lower DA value in the case of Choi et al. (2016), although this essential parameter was not precisely determined. The present study data collectively indicated no significant difference between the fibrin and fibrin-chitosan condition, suggesting that chitosan did not substantially modify the fibrin-triggered inflammatory response into the amputated DP tissue.

Chitosan modulates the functional activity of macrophages (Oliveira et al., 2012; Shibata et al., 1997). Macrophage polarisation is primordial in the early innate immune response after implantation of biomaterials (Brown et al., 2012; Witherel et al., 2016). The ability to polarise into M1 or M2 macrophages is associated with their morphology, marker expression and function (Ito et al., 2014; Takahashi et al., 1996). Pro-inflammatory M1 macrophages are antimicrobial and cytotoxic, while M2 macrophages are involved in inflammation resolution and tissue repair and have profibrotic action (Labonte et al., 
2014; Wynn et al., 2013). To clearly identify the M1 or M2 macrophage response to fibrin and fibrinchitosan hydrogels in the pulpotomised DP, the co-expression of specific markers (iNOS or CD163) was examined in association with CD68 and Iba1 by immunofluorescence. CD68 is currently considered to be a marker of all macrophages. Iba- 1 is a marker expressed on microglial cells and macrophages of the central nervous system (Hendrickx et al., 2017). It is associated with macrophage migration and phagocytic activity (Watano et al., 2001). In a previously described model of experimental ratinduced pulpitis, Iba-1-expressing macrophages were identified in healthy and experimentally inflamed DP (Renard et al., 2016). In the present study, iNOS cells were detected in the granulocytic inflammatory infiltrate $1 \mathrm{~d}$ after implantation but no cells coexpressing iNOS and CD68 and/or Iba-1 were found, suggesting the absence of M1 macrophages near fibrin or fibrin-chitosan hydrogels.

In other studies, M1 macrophages were detected until $3 \mathrm{~d}$ after pulpotomy and implantation of biodegradable porous poly-L-lactic acid scaffolds or hydrogels cellularised with bone marrow mesenchymal stem cells in rat molars. A shift to a M2 macrophage phenotype profile was observed thereafter (Gu et al., 2019). In a similar model, M2 macrophages transiently accumulated near the degenerative area under the capping material 1-2 d after a pulpotomy with MTA in rat molars (Takei et al., 2014). This accumulation suggested that M2 macrophages were involved in the initial phase of the healing process after DP capping.

In the present study, numerous M2 macrophages $\left(\mathrm{CD}_{68}^{+} \mathrm{Iba}^{+} \mathrm{1}^{+} \mathrm{CD} 163^{+}\right)$were observed in the DP close to the neutrophil granulocyte area $1 \mathrm{~d}$ after pulpotomy and fibrin or fibrin-chitosan hydrogel implantation. The promotion of M2 macrophages polarisation was previously demonstrated in contact with fibrin in vivo in mice as well as in vitro in humans (Tanaka et al., 2019) using a $5 \%$ DA chitosan scaffold (Vasconcelos et al., 2013) and a $15 \%$ DA chitosan scaffold supplemented with proresolution lipid mediators. Chitosan of high DA is not expected to promote M2 phenotype (Vasconcelos et al., 2015). Although a longer study duration may help describing pulp healing, the observation of M2 macrophages $1 \mathrm{~d}$ after pulpotomy highlights the absence of harmful effect related to the presence of $40 \%$ DA chitosan within the fibrin hydrogel. This point is crucial when considering tissue engineering of DP tissues after pulpotomy.

\section{Conclusion}

A previous study (Ducret et al., 2019) demonstrated that fibrin and fibrin-chitosan hydrogels support the adhesion and viability of DP-MSCs as well as the production of DP-like ECM in vitro. In the present study, chitosan added to fibrin hydrogels did not induce an early deleterious inflammatory/ immune response in DP. M2 macrophages, but not M1, were clearly identified close to the zone of neutrophil infiltration in contact with the hydrogels. This suggested that the latter could promote proregenerative macrophage phenotypes. Further studies are required to fully understand the role of immune cells, including M2 macrophages, in hydrogel degradation and replacement by a DP-like tissue in the context of pulpotomy.

\section{Acknowledgments}

The present work was supported by the French institute for dental research (IFRO). The authors would like to thank Aurélie Moreau for helpful discussions.

\section{References}

Aguilar A, Zein N, Harmouch E, Hafdi B, Bornert F, Offner D, Clauss F, Fioretti F, Huck O, BenkiraneJessel N, Hua G (2019) Application of chitosan in bone and dental engineering. Molecules 24: 3009. DOI: 10.3390/molecules24163009.

Albuquerque MTP, Valera MC, Nakashima M, Nör JE, Bottino MC (2014) Tissue-engineering-based strategies for regenerative endodontics. J Dent Res 93: 1222-1231.

Azuma MM, Samuel RO, Gomes-Filho JE, DezanJunior E, Cintra LTA (2014) The role of IL-6 on apical periodontitis: a systematic review. Int Endod J 47: 615-621.

Bjørndal L, Simon S, Tomson PL, Duncan HF (2019) Management of deep caries and the exposed pulp. Int Endod J 52: 949-973.

Braga JM, Oliveira RR, Martins RC, Ribeiro Sobrinho AP (2014) The effects of a mineral trioxide aggregate-based sealer on the production of reactive oxygen species, nitrogen species and cytokines by two macrophage subtypes. Int Endod J 47: 909-919.

Brizuela C, Ormeño A, Cabrera C, Cabezas R, Silva CI, Ramírez V, Mercade M (2017) Direct pulp capping with calcium hydroxide, mineral trioxide aggregate, and biodentine in permanent young teeth with caries: a randomized clinical trial. J Endod 43: 1776-1780.

Brown BN, Ratner BD, Goodman SB, Amar S, Badylak SF (2012) Macrophage polarization: an opportunity for improved outcomes in biomaterials and regenerative medicine. Biomaterials 33: 37923802.

Camilleri J, Formosa L, Damidot D (2013) The setting characteristics of MTA Plus in different environmental conditions. Int Endod J 46: 831-840.

Camilleri J, Grech L, Galea K, Keir D, Fenech M, Formosa L, Damidot D, Mallia B (2014) Porosity and root dentine to material interface assessment of calcium silicate-based root-end filling materials. Clin Oral Investig 18: 1437-1446. 
Chedly J, Soares S, Montembault A, von Boxberg Y, Veron-Ravaille M, Mouffle C, Benassy MN, Taxi J, David L, Nothias F (2017) Physical chitosan microhydrogels as scaffolds for spinal cord injury restoration and axon regeneration. Biomaterials 138: 91-107.

Choi B, Jo DH, Anower AKMM, Islam SMS, Sohn $S$ (2016) Chitosan as an immunomodulating adjuvant on T-cells and antigen-presenting cells in herpes simplex virus type 1 infection. Mediators Inflamm 2016: 4374375.

Čolić M, Gazivoda D, Vučević D, Vasilijić S, Rudolf R, Lukić A (2009) Proinflammatory and immunoregulatory mechanisms in periapical lesions. Mol Immunol 47: 101-113.

Colombo JS, Moore AN, Hartgerink JD, D'Souza RN (2014) Scaffolds to control inflammation and facilitate dental pulp regeneration. J Endod 40: 1-17.

Ducret M, Montembault A, Josse J, Pasdeloup M, Celle A, Benchrih R, Mallein-Gerin F, Alliot-Licht B, David L, Farges JC (2019) Design and characterization of a chitosan-enriched fibrin hydrogel for human dental pulp regeneration. Dent Mater 5: 523-533

Ducret M, Fabre H, Celle A, Mallein-Gerin F, Perrier-Groult E, Alliot-Licht B, Farges J-C (2017) Current challenges in human tooth revitalization. Biomed Mater Eng 28: S159-S168.

Farges J-C, Carrouel F, Keller J-F, Baudouin C, Msika P, Bleicher F, Staquet M-J (2011) Cytokine production by human odontoblast-like cells upon Toll-like receptor-2 engagement. Immunobiology 216: 513-517.

Farges JC, Alliot-Licht B, Renard E, Ducret M, Gaudin A, Smith AJ, Cooper PR (2015) Dental pulp defence and repair mechanisms in dental caries. Mediators Inflamm 2015: 230251. DOI: 10.1155/2015/230251.

Galler KM, Eidt A, Schmalz G (2014) Cell-free approaches for dental pulp tissue engineering. J Endod 40: 41-45.

Gaudin A, Renard E, Hill M, Bouchet-delbos L, Farges J, Cuturi M (2015) Phenotypic analysis of immunocompetent cells in healthy human dental pulp. J Endod 41: 621-627.

Giraud T, Jeanneau C, Rombouts C, Bakhtiar H, Laurent P, About I (2019) Pulp capping materials modulate the balance between inflammation and regeneration. Dent Mater 35: 24-35.

Gu B, Kaneko T, Zaw SYM, Sone PP, Murano H, Sueyama Y, Zaw ZCT, Okiji T (2019) Macrophage populations show an M1-to-M2 transition in an experimental model of coronal pulp tissue engineering with mesenchymal stem cells. Int Endod J 52: 504-514.

Hendrickx DAE, van Eden CG, Schuurman KG, Hamann J, Huitinga I (2017) Staining of HLA-DR, Iba1 and CD68 in human microglia reveals partially overlapping expression depending on cellular morphology and pathology. J Neuroimmunol 309: 12-22.

Hsieh JY, Smith TD, Meli VS, Tran TN, Botvinick EL, Liu WF (2017) Differential regulation of macrophage inflammatory activation by fibrin and fibrinogen. Acta Biomater 47: 14-24.

Ito T, Kaneko T, Yamanaka Y, Shigetani Y, Yoshiba K, Okiji T (2014) M2 macrophages participate in the biological tissue healing reaction to mineral trioxide aggregate. J Endod 40: 379-383.

Kawanishi HN, Kawashima N, Suzuki N, Suda H, Takagi M (2004) Effects of an inducible nitric oxide synthase inhibitor on experimentally induced rat pulpitis. Eur J Oral Sci 112: 332-337.

Kawashima N, Nakano-Kawanishi H, Suzuki N, Takagi M, Suda H (2005) Effect of NOS inhibitor on cytokine and COX2 expression in rat pulpitis. J Dent Res 84: 762-767.

Kunert M, Lukomska-Szymanska M (2020) Bio-inductive materials in direct and indirect pulp capping - a review article. Materials (Basel) 13: 1204. DOI: $10.3390 / \mathrm{ma} 13051204$.

Labonte AC, Tosello-Trampont AC, Hahn YS (2014) The role of macrophage polarization in infectious and inflammatory diseases. Mol Cells 37: 275-285.

Langub MC, Koszewski NJ, Turner H V, MonierFaugere MC, Geng Z, Malluche HH (1996) Bone resorption and mRNA expression of IL-6 and IL-6 receptor in patients with renal osteodystrophy. Kidney Int 50: 515-520.

Li Y, Sui B, Dahl C, Bergeron B, Shipman P, Niu L, Chen J, Tay FR (2019) Pulpotomy for carious pulp exposures in permanent teeth: a systematic review and meta-analysis. J Dent 84: 1-8.

Lopes CS, Junqueira MA, Cosme-Silva L, Pegoraro C de OR, Garbelini CCD, Oliveira TM, Martins NS, Neves J dos S, Sakai VT, Azevedo JM, Cosme-Silva L, Pegoraro C de OR, Garbelini CCD, Oliveira TM, Martins NS, Neves J dos S, Sakai VT (2019) Initial inflammatory response after the pulpotomy of rat molars with mta or ferric sulfate. J Appl Oral Sci 27: $1-11$.

Luiz de Oliveira da Rosa W, Machado da Silva T, Fernando Demarco F, Piva E, Fernandes da Silva A (2017) Could the application of bioactive molecules improve vital pulp therapy success? A systematic review. J Biomed Mater Res A 105: 941-956.

Matsuki Y, Yamamoto T (1992) Detection of inflammatory cytokine messenger RNA (mRNA)-expressing cells in human inflamed gingiva by combined in situ hybridization and immunohistochemistry. Immunology 76: 42-47.

Modena KC da S, Casas-Apayco LC, Atta MT, Costa CA de S, Hebling J, Sipert CR, Navarro MF de L, Santos CF (2009) Cytotoxicity and biocompatibility of direct and indirect pulp capping materials. J Appl Oral Sci 17: 544-554.

Morotomi T, Tabata Y, Kitamura C (2015) Dentinpulp complex regeneration therapy following pulp amputation. Adv Tech Biol Med 3: 3. DOI: 10.4172/2379-1764.100015.

Morotomi T, Washio A, Kitamura C (2019) Current and future options for dental pulp therapy. Jpn Dent Sci Rev 55: 5-11. 
Moussa DG, Aparicio C (2019) Present and future of tissue engineering scaffolds for dentin-pulp complex regeneration. J Tissue Eng Regen Med 13: 58-75.

Nowicka A, Lipski M, Parafiniuk M, SporniakTutak K, Lichota D, Kosierkiewicz A, Kaczmarek W, Buczkowska-Radlińska J (2013) Response of human dental pulp capped with biodentine and mineral trioxide aggregate. J Endod 39: 743-747.

Obersztyn A, Jedrzejczyk J (1968) Application of lyophilized dentin chips, mixed with prednisolone and neomycin, on infected rat incisor pulp. J Dent Res 47: 374-80.

Oliveira MI, Santos SG, Oliveira MJ, Torres AL, Barbosa MA (2012) Chitosan drives antiinflammatory macrophage polarization and proinflammatory dendritic cell stimulation. Eur Cells Mater 24: 136-153.

Parirokh M, Torabinejad M, Dummer PMH (2018) Mineral trioxide aggregate and other bioactive endodontic cements: an updated overview - part I: vital pulp therapy. Int Endod J 51: 177-205.

Rechenberg D-K, Galicia JC, Peters OA (2016) Biological markers for pulpal inflammation: a systematic review. PLoS One 11: e0167289. DOI: 10.1371/journal.pone.0167289.

Renard E, Gaudin A, Bienvenu G, Amiaud J, Farges JC, Cuturi MC, Moreau A, Alliot-Licht B (2016) Immune cells and molecular networks in experimentally induced pulpitis. J Dent Res 95: 196205.

Scott P, Trinchieri G (1995) The role of natural killer cells in host-parasite interactions. Curr Opin Immunol 7: 34-40.

Shah D, Lynd T, Ho D, Chen J, Vines J, Jung H-D, Kim J-H, Zhang P, Wu H, Jun H-W, Cheon K (2020) Pulp-dentin tissue healing response: a discussion of current biomedical approaches. J Clin Med 9: 434. DOI: $10.3390 / j \mathrm{~cm} 9020434$.

Shibata Y, Foster LA, Metzger WJ, Myrvik QN (1997) Alveolar macrophage priming by intravenous administration of chitin particles, polymers of $\mathrm{N}$-acetyl-D-glucosamine, in mice. Infect Immun 65: 1734-1741.

Sierra-Filardi E, Nieto C, Domínguez-Soto Á, Barroso R, Sánchez-Mateos P, Puig-Kroger A, LópezBravo M, Joven J, Ardavín C, Rodríguez-Fernández JL, Sánchez-Torres C, Mellado M, Corbí ÁL (2014) CCL2 shapes macrophage polarization by GM-CSF and M-CSF: identification of CCL2/CCR2-dependent gene expression profile. J Immunol 192: 3858-3867.

Simon S, Perard M, Zanini M, Smith a J, Charpentier E, Djole SX, Lumley PJ (2012) Should pulp chamber pulpotomy be seen as a permanent treatment? Some preliminary thoughts. Int Endod J 46: 79-87.

Takahashi K, Naito M, Takeya M (1996) Development and heterogeneity of macrophages and their related cells through their differentiation pathways. Pathol Int 46: 473-485.

Takei E, Shigetani Y, Yoshiba K, Hinata G, Yoshiba N, Okiji T (2014) Initial transient accumulation of M2 macrophage-associated molecule-expressing cells after pulpotomy with mineral trioxide aggregate in rat molars. J Endod 40: 1983-1988.

Takimoto K, Kawashima N, Suzuki N, Koizumi Y, Yamamoto M, Nakashima M, Suda H (2014) Down-regulation of inflammatory mediator synthesis and infiltration of inflammatory cells by MMP-3 in experimentally induced rat pulpitis. J Endod 40: 14049.

Tanaka R, Saito Y, Fujiwara Y, Jo J ichiro, Tabata Y (2019) Preparation of fibrin hydrogels to promote the recruitment of anti-inflammatory macrophages. Acta Biomater 89: 152-165.

Tran X V, Gorin C, Willig C, Baroukh B, Pellat B, Decup F, Opsahl Vital S, Chaussain C, Boukpessi T (2012) Effect of a calcium-silicate-based restorative cement on pulp repair. J Dent Res 91: 1166-1171.

Vasconcelos DP, Costa M, Amaral IF, Barbosa MA, Águas AP, Barbosa JN (2015) Modulation of the inflammatory response to chitosan through M2 macrophage polarization using pro-resolution mediators. Biomaterials 37: 116-123.

Vasconcelos DP, Fonseca AC, Costa M, Amaral IF, Barbosa MA, Águas AP, Barbosa JN (2013) Macrophage polarization following chitosan implantation. Biomaterials 34: 9952-9959.

Verma P, Nosrat A, Kim JRR, Price JBB, Wang P, Bair E, Xu HHH, Fouad AF (2017) Effect of residual bacteria on the outcome of pulp regeneration in vivo. J Dent Res 96: 100-106.

Vishwanat L, Duong R, Takimoto K, Phillips L, Espitia CO, Diogenes A, Ruparel SB, Kolodrubetz D, Ruparel NB (2017) Effect of bacterial biofilm on the osteogenic differentiation of stem cells of apical papilla. J Endod 4: 916-922.

Watano K, Iwabuchi K, Fujii S, Ishimori N, Mitsuhashi S, Ato M, Kitabatake A, Onoé K (2001) Allograft inflammatory factor-1 augments production of interleukin- $6,-10$ and -12 by a mouse macrophage line. Immunology 104: 307-316.

Wisithphrom K, Murray PE, Windsor LJ (2006) Interleukin-1 alpha alters the expression of matrix metalloproteinases and collagen degradation by pulp fibroblasts. J Endod 32: 186-192.

Witherel CE, Graney PL, Freytes DO, Weingarten MS, Spiller KL (2016) Response of human macrophages to wound matrices in vitro. Wound Repair Regen 24: 514-524.

Wynn TA, Chawla A, Pollard JW (2013) Macrophage biology in development, homeostasis and disease. Nature 496: 445-455.

Xu H, Chen J, Ge J, Xia K, Tao S, Su Y, Zhang Q (2019) Resolvin E1 ameliorates pulpitis by suppressing dental pulp fibroblast activation in a chemerin receptor 23-dependent manner. J Endod 45: 1126-1134.e1. DOI: 10.1016/j.joen.2019.05.005.

Yang J, Yuan G, Chen Z (2016) Pulp regeneration: current approaches and future challenges. Front Physiol 7: 58. DOI: 10.3389/fphys.2016.00058.

Yeh HW, Chiang CF, Chen PH, Su CC, Wu YC, Chou L, Huang RY, Liu SY, Shieh YS (2018) Axl 
involved in mineral trioxide aggregate induces macrophage polarization. J Endod 44: 1542-1548.

Zheng L, Amano K, Iohara K, Ito M, Imabayashi K, Into T, Matsushita K, Nakamura H, Nakashima M (2009) Matrix metalloproteinase-3 accelerates wound healing following dental pulp injury. Am J Pathol 175: 1905-1914.

Zhu X, Yuan Z, Yan P, Li Y, Jiang H, Huang $S$ (2017) Effect of iRoot SP and mineral trioxide aggregate (MTA) on the viability and polarization of macrophages. Arch Oral Biol 80: 27-33.

\section{Discussion with Reviewers}

Pierfrancesco Pagella: It is interesting to evaluate short-term immune responses to the hydrogels used. However, successful pulp regeneration would require more than $3 \mathrm{~h}$ or $1 \mathrm{~d}$. Thus, it would be of extreme interest to study the long-term effect of the hydrogels tested and/or possible chronic immune responses. Can the authors comment on the differences between short-term and long-term immune responses to hydrogels? How can the results observed at 3 and $24 \mathrm{~h}$ be projected to longer periods?

Authors: Successful pulp regeneration would require more than $3 \mathrm{~h}$ or $1 \mathrm{~d}$. In the current work, addition of chitosan to fibrin hydrogels did not induce an early deleterious inflammatory/immune response in the DP. This was the first and crucial step before assessing the regenerative potential following longer time points. The final aim of the present study was regeneration of pulp connective-tissue, dentine, radicular edification, vascularisation and innervation. Hydrogels are widely used as scaffolds in tissue engineering. They are essential for delivering active molecules and for carrying competent cells within the endodontic pulp space. Besides their physical features (adequate viscosity, allowing their injection in the whole root canal system as well as porosity, which is crucial for cell colonisation), they must also promote biological effect in order to gain regenerated DP-like tissues. Recently, chitosan-based scaffolds have been developed for this purpose (Aguilar et al., 2019; Ducret et al., 2019). In addition, several recent reports (Aguilar et al., 2019; Ducret et al., 2019; Fakhri et al., 2019, additional reference) have demonstrated that chitosan-based scaffolds promote the odontoblastic differentiation of DP stem cells and MSCs both in vitro and in vivo. Also, chitosan may be considered to be a vector for antimicrobials and, thus, completing the "classic triad" of tissue engineering to the "quartet of tissue engineering in endodontics", as defined by Diogenes and Hargreaves (2017), where disinfection is a fundamental part of regenerative endodontics, interacting with the interplay between stem cells, scaffolds and growth factors.

To assess the potential of chitosan-enriched fibrin hydrogel as a promising strategy in regenerative endodontics, different step should be considered. Proof of concept, design, formulation and in vitro assessment have already been validated (Ducret et al., 2019). Although hydrogels are reported to be well-suited for tissue engineering and are supposed not to induce or induce only a low inflammatory response (Caló et al., 2015; Kashyap et al., 2005; Liu et al., 2016; Xue et al., 2019, additional references), addition of chitosan to fibrin hydrogel has not been explored in regenerative endodontics. Therefore, it was crucial to determine its effect on inflammatory/ immune response in the DP tissue before long-term assessment. In the present work, addition of chitosan to fibrin hydrogels did not induce a deleterious inflammatory/immune response in the DP. M2 macrophages, but not M1, were clearly identified close to the zone of neutrophils infiltration in contact with the hydrogels, suggesting that the latter are able to promote pro-regenerative macrophage phenotypes. Further investigations are required to fully understand the role of immune cells, including M2 macrophages, in hydrogel degradation and replacement by a DP-like tissue in the context of pulpotomy.

In this context, the surgical procedure and the hydrogel itself lead to an acute inflammatory response that may be followed in some cases by a chronic inflammatory response and/or granulation tissue formation as well as fibrous capsule development. The resolution of such inflammatory response is necessary to re-establish homeostasis, limiting excessive tissue injury, minimising the development of chronic inflammation and allowing for tissue repair and regeneration. Several reports provide evidence that delivery of biological therapeutics using hydrogels and scaffolds could actively regulate the kinetics of multiple steps in the immune response (Chalovich and Eisenberg, 2005; Follin et al., 2016; Singh and Peppas, 2014, additional references). Although the present study demonstrated that short-term evaluation was promising, a longer-term evaluation should focus on kinetic degradation and conditions of degradation. Indeed, these conditions could potentially affect the recruitment, infiltration, phagocytosis and homing of immune cells in response to hydrogels. Neovascularisation, mineralising ability and long-term regenerative potential require in vivo assessment using different models to mimics the translation to human therapeutic.

Reviewer 2: Authors should perform experiments on the expression of IL- 6 at different time point, not only after $3 \mathrm{~h}$ after implantation, e.g. after $24 \mathrm{~h}$.

Authors: Ideally, the optimal assessment for IL-6 would have been at different time point. Similarly to Xu et al. (2019), additional time points (0, 3, 9, 24 and $48 \mathrm{~h}$ ) may have been considered. Indeed, assessment of IL-6 expression is relevant when considering DP inflammatory/immune response to biomaterials (Gomes-Filho et al., 2009; Sanz et al., 2020, additional references). IL-6 is a pleiotropic cytokine produced by a variety of immune and non-immune cells (macrophages, neutrophils, keratinocytes, fibroblasts, 
endothelial cells, odontoblasts) (Farges et al., 2011; Matsuki and Yamamoto, 1992) in response to stimuli such as infection and trauma. IL-6 regulates many aspects of the local immune response (Langub et al., 1996) and has been found in inflamed pulp tissue and periapical lesions (Azuma et al., 2014; Čolić et al., 2009; Wisithphrom et al., 2006). IL-6 controls the recruitment of neutrophils and induces $B$ and T lymphocyte differentiation. IL-6 is considered to be both a pro- and anti-inflammatory cytokine; it is produced during inflammation and after TNF- $\alpha$ and IL- 1 secretion. For this reason, IL- 6 expression was assessed in response to chitosan-enriched fibrin hydrogel in pulpotomised rat incisors. Several other investigations may also have been conducted (protein expression with ELISA; location with immunohistology). However, the present study focused more on cytokine network that may play a significant role in immune response rather than a specific analysis of IL-6 in response to an acute inflammation related to pulpotomy and chitosanenriched fibrin hydrogels. Moreover, the increase in IL-6 expression was similar for short-time assessment ( 3 and $9 \mathrm{~h}$ ) in a previous published study (Renard et al., 2016). This result is in agreement with Kawashima et al. (2005), who used a similar inflammatory model in rodent incisors. Lastly, considering ethical aspects and 3 Rs rules, the number of time points was limited as much as possible but to be nevertheless sufficient for a diverse evaluation (cytokine network, cellular level by FACS and M1/M2 polarisation by immunohistology). In the present study, addition of chitosan to fibrin hydrogels did not induce a deleterious inflammatory/immune response in the DP. This was the first and crucial step before assessing the regenerative potential with longer time points. Longer time point for IL-6 expression will be considered for future experiments since it has been suggested that IL-6 is a suitable indicator of pulp condition and its monitoring may enhance the accuracy of prognosis of vital-pulp therapy (Ozdemir et al., 2015, additional reference).

\section{Additional References}

Caló E, Khutoryanskiy V V (2015) Biomedical applications of hydrogels: a review of patents and commercial products. Eur Polym J 65: 252-267.
Chalovich JM, Eisenberg E (2005) Hydrogels and scaffolds for immunomodulation. Biophys Chem 257: 2432-2437.

Fakhri E, Eslami H, Maroufi P, Pakdel F, Taghizadeh S, Ganbarov K, Yousefi M, Tanomand A, Yousefi B, Mahmoudi S, Kafil HS (2020) Chitosan biomaterials application in dentistry. Int J Biol Macromol 162: 956-974.

Follin B, Juhl M, Cohen S, Perdersen AE, Kastrup J, Ekblond A (2016) Increased paracrine immunomodulatory potential of mesenchymal stromal cells in three-dimensional culture. Tissue Eng Part B Rev 22: 322-329.

Gomes-Filho JE, Watanabe S, Gomes AC, Faria MD, Lodi CS, Penha Oliveira SH (2009) Evaluation of the effects of endodontic materials on fibroblast viability and cytokine production. J Endod 35: 15771579

Kashyap N, Kumar N, Kumar MNVR (2005) Hydrogels for pharmaceutical and biomedical applications. Crit Rev Ther Drug Carrier Syst 22: 107-149.

Liu L, Gao Q, Lu X, Zhou H (2016) In situ forming hydrogels based on chitosan for drug delivery and tissue regeneration. Asian J Pharm Sci 11: 1-11.

Ozdemir Y, Kutukculer N, Topalogu-Ak A, Kose T, Eronat C (2015) Comparative evaluation of pro-inflammatory cytokine levels in pulpotomized primary molars 57: 145-150.

Sanz JL, Forner L, Almudéver A, GuerreroGironés J, Llena C (2020) Viability and stimulation of human stem cells from the apical papilla (hscaps) induced by silicate-based materials for their potential use in regenerative endodontics: a systematic review. Materials (Basel) 13: 1-15.

Singh A, Peppas NA (2014) Hydrogels and scaffolds for immunomodulation. Adv Mater 26: 6530-6541.

Xue K, Wang X, Yong PW, Young DJ, Wu Y-L, Li Z, Loh XJ (2019) Hydrogels as emerging materials for translational biomedicine. Adv Ther 2: 1800088 . DOI: 10.1002/adtp.201800088.

Editor's note: The Scientific Editor responsible for this paper was Thimios Mitsiadis. 